Article

\title{
Inequalities and Child Protection System Contact in Aotearoa New Zealand: Developing a Conceptual Framework and Research Agenda
}

\author{
Emily Keddell ${ }^{1, *}$ and Gabrielle Davie ${ }^{2}$ \\ 1 Department of Sociology, Gender and Social Work, University of Otago, PO Box 56, Dunedin 9054, \\ Aotearoa, New Zealand \\ 2 Dunedin School of Medicine, University of Otago, PO Box 56, Dunedin 9054, Aotearoa, New Zealand; \\ gabrielle.davie@otago.ac.nz \\ * Correspondence: emily.keddell@otago.ac.nz; Tel.: +64-3-4795867
}

Received: 24 April 2018; Accepted: 25 May 2018; Published: 1 June 2018

\begin{abstract}
There is a growing movement to integrate conceptual tools from the health inequalities field into research that examines the relationship between inequalities and chances of child protection system contact. This article outlines the key concepts of an inequalities perspective, and discusses how these apply to inequalities in child protection in the Aotearoa New Zealand context. Drawing on existing research, this article shows that while there is evidence of links between deprivation, ethnicity, location and system contact, a more systematic research agenda shaped by an inequalities perspective would contribute to understanding more fully the social determinants of contact with the child protection system. An inequalities perspective provides balance to the current 'social investment' policy approach that targets individuals and families for service provision, with little attention to how structural inequalities impact on system contact. Directions for research are discussed, with some specific questions suggested. These include questions relating to the relationships between social inequalities and various decision points in the child protection system; if a social gradient exists and how steep it is; the inter-relationship between ethnicity, deprivation and patterns of system contact; and how similarly deprived children in different locations compare with each other in relation to child protection system contact, that is, is there an 'inverse intervention law' operating?
\end{abstract}

Keywords: child protection; deprivation; ethnicity; poverty; social investment

\section{Introduction}

Child protection system interventions are increasingly prevalent in many countries, but this prevalence is not evenly shared across the population. While it is clear that inequalities relating to deprivation, ethnicity and others influence contact with child protection services generally, understanding their complexities in specific national contexts is important so that research and policy strategies are developed in a manner responsive to specific environments. This article draws on international and national research to explore the following key questions: What is an inequalities perspective, and what can it add as a conceptual framework to understanding the chances of child protection system contact in Aotearoa New Zealand? What existing evidence is there about inequalities relating to deprivation, ethnicity and other axes of inequality, and contact with child protection systems? What gaps are there in our knowledge that require research attention?

The population in contact with child protection systems is a diverse and growing one. As definitions and types of abuse have expanded, and expectations of the state to protect children have risen, the rates of children notified to child protection services in Anglophone countries have generally increased (Gilbert 2012; Melton 2005). In some instances, this has led to heightened strain on child 
protection agencies, multiple re-referrals, and more children in foster care, driving many countries to re-think their child welfare systems (Bilson and Martin 2016; Gilbert et al. 2011; Parton 2010a, 2010b; Spratt 2008).

When comparing Aotearoa New Zealand to broad international trends, similarities and differences emerge. Overall, high rates of children have some kind of child protection system contact. For a 1990-1991 birth cohort, it was found that 15\% of all children had been notified at some point in their childhood, with $7 \%$ of children having a substantiated finding of abuse. Later cohorts are estimated to have even higher rates, with $20 \%$ of a 1993 cohort being notified (Templeton et al. 2016). The latest published research states the rates for a cohort born in 1998 until the end of 2015. The authors found that $23.5 \%$ of children had at least one notification, and $9.7 \%$ had a substantiated finding (Rouland and Vaithianathan 2018). Ethnic inequities are marked, with 28\% of Māori children, 12\% of European, $18 \%$ of Pacific and $4 \%$ of Asian children having some form of contact with the child protection system (Templeton et al. 2016). This pattern of system contact generally shows an increase over time of notifications and substantiations.

How does this rate compare internationally? Bilson and Martin (2016) found that in the UK, $22.5 \%$ of children were notified in a 2010 cohort and $7.8 \%$ substantiated, but this was only by age 5 , suggesting the overall childhood rate may be somewhat higher than in Aotearoa New Zealand. A Western Australian study of a 1990-1991 cohort found that 13\% of all children were reported before reaching the age of eighteen, with only $3 \%$ substantiated. Bilson and Martin (2016) note the increasing proportions of children investigated or notified but not substantiated. This has occurred in Aotearoa New Zealand, with the proportion of notifications not substantiated increasing slightly from $53 \%$ of the $1990-1991$ cohort, to $59 \%$ of the 1998 cohort.

Bilson and Martin (2016) point out that while child protection systems are an important element of state responses to children's needs, they focus intensely on forensic investigations with few responses to address the pressing social needs that are the antecedents to child protection system contact. They observe that there is often less emphasis on prevention, resulting in more children placed in out of home care. In light of this, they argue for "... a change from the current emphasis on individualised and investigative approaches to child protection in order to provide an effective and humane response to children, the majority of whom live in families affected by high levels of deprivation and poverty" (Bilson and Martin 2016, p. 793). Bywaters et al. (2016a) show that deprivation has a marked correlation with contact with the child protection system in England, occurring along a social gradient where those more deprived had higher rates of contact than less deprived children. While this basic correlation is unsurprising, there has been little recent research into either the extent or the underlying causes of child protection inequalities, and "a reluctance to describe differences as inequalities or to propose action on the underlying social determinants" (Bywaters 2013, p. 6). The development of an inequalities perspective in relation to these important questions, as is well established in health, opens up a range of research and policy directions important to promote equity and effectiveness in relation to child protection in Aotearoa New Zealand. An inequalities perspective draws focus to the social determinants of system contact, and can assist with balanced policy responses that address these determinants in addition to family or individual factors.

\section{Key Features of the Inequalities Perspective}

The inequalities perspective prominent in health research and policy includes several key features (Bywaters et al. 2009). It draws attention to the relationship between socio-economic circumstances and particular features of people's daily lives-for example, in patterns of income and wealth, employment, health or education or in child welfare and child protection-but it does so not by focusing only on those at the bottom of the spectrum of advantage but by looking across the population. This raises such questions as how is income, wealth, health, education and good childhood development distributed across society? What are the patterns associated with middle or higher incomes as well as the implications of living in poverty? This draws attention away from focusing only on the reasons 
why some people do badly to question also why others do well. This balance of emphasis should remove the problem of 'othering' from the discussion of social phenomena that can develop when socioeconomic differences are presented as dichotomous categories.

In the child welfare field, this opens up a series of issues. First, this leads to a focus on child development and opportunities across families in all social circumstances, not only on those living in poverty. Some assume that contact with child protection services is reserved for a very small minority of children and that most of those are in very disadvantaged circumstances but recent English research has suggested that at least $40 \%$ of all children subject to child protection plans will be living in neighbourhoods outside the most disadvantaged 20\% in the country (Bywaters et al. 2015).

Second, an inequalities perspective aims to establish the social gradient of the phenomenon under examination (Roberts 2012). The social gradient is a measure of how much difference an increase in social advantage or disadvantage makes to the chosen outcome. The magnitude of the social gradient bears on the allocation of resources but it should also raise questions about the interaction of family disadvantage and other factors-universal and targeted service patterns and priorities, parental skills and attitudes or education, or the availability of informal sources of support at different points in the economic spectrum or in different ethnic communities, for example. This opens up discussion about the relative difference between people across the whole spectrum, not only on those at the extremes, and links this to the supply and demand of services. In this way, it should question not only what percentage of people receiving child protection interventions are in poverty, but how great is the difference in the percentages between those who are most deprived and those at other points on the deprivation spectrum? Given that abuse and neglect are found in families with very different social circumstances, what should be the proportionate allocation of resources and services between different parts of society?

Third, the related question to those concerning the social gradient is the question of whether there is an interdependent relationship between outcomes for different groups: do some people do worse as a consequence of others doing better? For example, if child development is measured in terms of middle-class family values, does this pre-dispose working class families to more negative consequences of involvement with social work services (Bradt et al. 2015)?

A fourth key concept in an inequalities perspective is the concept of intersectionality: the interaction of different dimensions of structured social relations, for example, deprivation with ethnicity, gender, disability, age or sexual orientation (Nadan et al. 2015). The question here is how these varied aspects of people's identities interact with socio-economic inequalities to contribute to unequal outcomes. In child protection, child gender differences in child outcomes appear to be surprisingly small by comparison with differences between ethnic groups, or between disabled and non-disabled children.

A fifth concept relates to the explanatory theories we use to understand inequalities in rates of system contact. Child welfare inequalities research describes differences in rates, but also attempts to explain differences in rates by examining the complex interplay between increased actual exposure to risk factors (and therefore incidence) for some groups, bias within the systems that respond to them, and the structural factors that shape supply and demand of services (Boyd 2014; Bywaters et al. 2015; Cram et al. 2015; Drake et al. 2011). The supply of services—the availability, appropriateness and accessibility of services, both formal statutory child protection services, and prevention services-also influences variations in intervention rates and their outcomes (National Audit Office 2016; Fluke et al. 2010). Services may contribute to exacerbating inequalities when they are not designed or applied in proportion to the level of need in different geographical areas, or different social groups. For example, studies in England have found evidence of an 'inverse intervention law' (Bywaters et al. 2015), that is, that local authorities that have high average deprivation also have higher rates of children on child protection plans. But when similarly advantaged or disadvantaged neighbourhoods (small areas within local authorities) are compared between local 
authorities, the low deprivation local authorities have been found to have much higher rates of intervention than local authorities with high deprivation overall.

Finally, there is the question of whether the degree of income inequality in a population is an additional contributory factor over and above the dimensions of socio-economic circumstances and ethnicity already mentioned. Does a society with high income inequality produce worse (or better, some might argue) outcomes for people at different places on the social spectrum over and above just the consequences of their circumstances? (Wilkinson and Pickett 2009). For example, if a society is more unequal is there the potential for greater shame, guilt or distress at any given level of disadvantage, further reinforcing the negative effects of a disadvantaged position, than if there is a sense that (almost) everyone faces not too dissimilar odds? There is some-limited-evidence in the child protection field that the degree of inequality in a society creates such additional strains on family life (Eckenrode et al. 2014; Peacock et al. 2014).

A nuanced conceptual framework needs to be developed to explore the interaction of social, economic and environmental inequalities in family resources, with patterns of policy and service priorities, resources and practices to produce outcomes. Bywaters et al. (2016d) note that an important overarching question is: do services reflect, reinforce or reduce inequalities?

\section{Child Welfare Research Using an Inequalities Framework}

As mentioned above, recent research has drawn on this perspective to examine the complex relationships between social, economic and environmental inequalities and child welfare outcomes for children. This research direction seeks to understand how inequalities affect the chances of children's contact with this system, their experiences once they are in it, and the outcomes of that contact (Bywaters et al. 2015, 2016a, 2016b, 2016c, 2018). Elsewhere, particularly in the US, many studies have examined the intersecting influences of poverty, income and race on contact with the child protection system (Cancian et al. 2013; Conrad-Hiebner and Paschall 2017; Detlaff et al. 2011; Font et al. 2012; Pelton 2015; Raissian and Bullinger 2016; Slack et al. 2017). While these US studies do not explicitly state an inequalities perspective, nevertheless they highlight the ways that contact with the child protection system is shaped by socio-structural factors, adding to our understanding of the causes of system contact and its outcomes. For example, Pelton (2015) examines the interplay of deprivation and ethnicity. He concludes that findings assessing the importance of racial bias as an explanatory factor are mixed " ... but leave no doubt that racial disproportionalities within the system are overwhelmingly related to racial disproportionalities in the poverty population. There is continuing evidence that children placed in foster care are predominantly from impoverished families, and that changes in the level of material supports are related to risk of placement" (p. 30).

Others also draw attention to the role of neighbourhood differences in relation to inequalities. They explicate nuanced evidence showing the interactions of neighbourhood factors, such as social cohesion, ethnic diversity, transience and adult:child ratios, with poverty to shape child welfare outcomes (Coulton et al. 2007; Maguire-Jack and Font 2017; Molnar et al. 2016; Shuey and Leventhal 2017). For example, Shuey and Leventhal (2017) using multilevel path models found that wealthier neighborhoods were "indirectly associated with mothers' lower reports of physical aggression with their children via more neighborhood services for children" (p. 52). Klein and Merritt (2014) found that risk of referral to child protection services increased for Black, White and Hispanic US children if they lived in multicultural, as opposed to ethnically homogenous, neighborhoods. Molnar et al. (2016) showed that social neighborhood processes such as intergenerational closure, collective efficacy and social networks were correlated with lower rates of all types of abuse substantiations.

Building on these descriptive studies, researchers have attempted to theorise why inequalities have a relationship with child welfare services interventions. Proposed explanations as mentioned above include: the increased risk of exposure to poverty as a life stressor increasing actual incidence, (both for poorer people overall, and people from ethnic minorities overrepresented in this group); the impact of other services available to less deprived people outside of the child welfare system; 
differences in demand and supply of child welfare services; the heightened surveillance more deprived people are exposed to; and the role of bias within the systems that respond to them, of both referrers, and decision-makers within the child protection system (Boyd 2014; Detlaff 2014; Drake et al. 2009; Johnson-Reid et al. 2009; Wells et al. 2009; Widom et al. 2015). Understanding how inequalities interact with decision-making is important. For example, Morris et al. (2018) are researching how site-specific decision-making processes at wealthier and more deprived sites interact with deprivation to affect the chance of children having child welfare system contact. Examining how social workers perceive and respond to poverty in the context of family life is an important aspect of the study. Stokes and Schmidt (2011) found that while neither race nor poverty directly affected decision-makers, nevertheless other indicators of deprivation such as substandard housing and substance abuse did affect decision-reasoning, suggesting that "The increasingly technocratic discourse in child protection blames individual parents and holds them responsible for not protecting their child from vulnerability, regardless of any historical and structural impediments they may face in attaining adequate resources" (p. 1105). One direction for inequalities research is to draw attention to the interplay between macro contexts, policies, discourses that frame the causes and consequences of child abuse, and decision-making practices.

\section{The Aotearoa New Zealand Context}

The macro conditions operating in Aotearoa New Zealand point to a concerning picture, one in which it is pressing to consider the impact of a range of inequalities on the chances of child protection contact and its outcomes. Current policy directions use administrative data to target individuals for service receipt within a 'social investment' approach aimed at reducing future cost to the state; however, the broader social context that contributes to social problems is largely invisible in this policy plan (O'Brien 2016; Keddell 2017). This section outlines the broad macro factors contributing to structural inequalities. It examines current research into variations in child protection system contact that may be related to inequalities, and what is already known about the risk, bias and spatial processes that influence children's chances of being in contact with the child protection system.

Aotearoa New Zealand has high levels of child poverty, with $28 \%$ of children living below the $60 \%$ median wage (after housing costs) relative poverty line in 2015, up from $24 \%$ three years earlier (Simpson et al. 2016). This rate is not evenly distributed by ethnicity, with 33\% of Māori (indigenous), $28 \%$ of Pasifika (Pacific) and 16\% of Pākeha (European ancestry) children living in households in income poverty. Of children living in households in income poverty, 46\% are Māori or Pacific (Perry 2015). Of all children, $14 \%$ are in material hardship, that is, going without the things most New Zealanders consider essential (Simpson et al. 2015). Auckland, the largest city in Aotearoa New Zealand, has the most unaffordable housing in the world based on the ratio of household income: housing cost, with the average house price equal to ten times the average household income (Collins 2014). The result of this is high rates of homelessness and fragile housing situations. Differences in rates of childhood illnesses and educational success are marked between different levels of deprivation, for example, Aotearoa New Zealand has a rate of bronchiectasis that is 9 times that of Finland, and rates of rheumatic fever generally not seen in 'developed' countries (Dale et al. 2014).

\section{Inequalities in Contact with the Child Protection System in Aotearoa New Zealand}

In this context of poor social conditions, and in the context of extensive reforms of the child protection system, what is the relationship between inequalities relating to deprivation and ethnicity particularly, and contact with the child protection system (Expert Panel 2015)? Aotearoa NZ has a depth of research in the health inequalities area, yet translating this into examining child protection has so far been limited (Dew and Matheson 2009; Dew et al. 2016; Woodward and Blakely 2016). This section outlines patterns of system contact overall, before examining some of the research already undertaken in relation to deprivation, ethnicity and child protection system contact. 
Patterns of contact with child protection services in Aotearoa New Zealand have generally increased over the last twenty years. As mentioned above, a recent study of a birth cohort of children born in Aotearoa New Zealand in 1998 found that 23.5\% of those children had some contact with child protection services before age 18 , and $9.7 \%$ had a substantiated finding of abuse (Rouland and Vaithianathan 2018). In other research it is apparent that many children have multiple notifications. Of those 28,079 children engaged with the statutory agency in 2016, 70\% had been previously notified, on average six times (Crichton et al. 2016). While notifications have risen between the 1990-1998 cohort studies, there is evidence of a decline in very recent years, as raw numbers of notifications, substantiations, child and family assessments or further investigations, all reduced by between ten and nineteen percent in the years 2016 to 2017, with a shallower decline in all these decision points since 2012 (Ministry of Social Development 2018). Children having Family Group Conferences (FGCs) and in foster care, on the other hand, have increased, the first by $4 \%$ and the second by $8 \%$ between 2016 and 2017 (Ministry of Social Development 2018). The reduction in earlier points of system contact may be shaped by the reforms mentioned above. These reforms (the Vulnerable Children's Reform and the Modernising Child Youth and Family reforms) aim to 'head off' children before they enter the child protection system, via mechanisms such as children's teams (professional teams outside of the statutory service), or changes in the decision-making tools available at entry (Sturmfels, pers.com., 2016). However, there has been little increase in the funding of preventive services -contracted non-governmental organisations have had no cost of living index increase to their contracts since 2008. This, combined with the lack of direct services available via the Children's Teams may be resulting in the threshold for entry to child protection services rising, but once children are over that threshold, an increased likelihood of entry to care and remaining in care longer. This conclusion is also suggested by the fact that the increases to children in care reflect a stable rate of entry to care, but fewer children leaving care (Ministry of Social Development 2018). The increase of FGCs and placement may be the first effects of the recent changes that aim to move children more quickly into permanent care arrangements once they have system contact (Expert Panel 2015). These patterns reflect that policies, resources and decision-making practices may interact with inequalities, operating together to shape both the reasons families are notified, and decision-making pathways post-notification (Putnam-Hornstein et al. 2013; Slack et al. 2017). More research however, is needed to properly understand the dynamic processes shaping system interactions in Aotearoa New Zealand, as these conclusions are at best tentative.

There are considerable spatial, temporal, ethnic and placement type variations in child protection system contact within Aotearoa New Zealand, also suggesting a relationship between system contact and inequalities. For example, as seen in Table 1, there are differences in child protection substantiations relative to notifications in different regions of the country, and over time. These range from $17 \%$ in Canterbury, to $38 \%$ in Counties Manukau in 2013. In 2017, the variation was from 10\% in Canterbury to $21 \%$ in Bay of Plenty and Waitemata. Different site offices show even more variation, with the proportion of notifications that are substantiated ranging from 16\% in Timaru (a town in the southern region) to 54\% in Taumarunui (a town in the Central region) in 2015. There are also variations between rates of substantiated findings as a proportion of total child population by each site office, from 5 per 1000 children in Alexandra, to 62 per 1000 children in Taumarunui (in 2015) (Ministry of Social Development 2016). What causes such marked differences in substantiation rates? They may be related to differing levels of exposure to risks such as poverty, surveillance or system bias, site-specific differences in processing cases through the system, differences in the balance between demand and supply of services, or a combination of all these elements (McLaughlin and Jonson-Reid 2017; Kim et al. 2018). Examining these differences from an inequalities perspective helps ascertain what the structural contributors are to these patterns. 
Table 1. Total children with substantiations (subs) as a percentage of reports of concern (RoC) by operational area in Aotearoa NZ 2013, 2015, $2017^{*}$.

\begin{tabular}{cccccccc}
\hline Region & Operational Area & $\mathbf{2 0 1 3} \mathbf{R o C}$ & \% Subs & $\mathbf{2 0 1 5}$ RoC & \% Subs & 2017 ROC & \% Subs \\
\hline Te Tai Tokerau & Te Tai Tokerau & 6578 & 24 & 5973 & 16 & 5751 & 19 \\
Auckland Region & Waitemata & 13,150 & 24 & 11,117 & 19 & 10,785 & 21 \\
Auckland Region & Counties Manukau & 14,416 & 38 & 12,234 & 24 & 12,037 & 20 \\
Midlands Region & Waikato & 7768 & 25 & 7619 & 23 & 7597 & 20 \\
Midlands Region & Bay of Plenty & 9848 & 31 & 9257 & 24 & 8646 & 21 \\
Central Region & Western & 4341 & 22 & 4421 & 18 & 4205 & 17 \\
Central Region & Eastern & 5406 & 20 & 6305 & 20 & 6004 & 18 \\
Central Region & Lower North Island & 4536 & 20 & 4392 & 19 & 4033 & 19 \\
Central Region & Greater Wellington & 5966 & 24 & 5538 & 23 & 5385 & 18 \\
Southern Region & Upper South & 3974 & 18 & 3379 & 16 & 3195 & 19 \\
Southern Region & Canterbury & 9854 & 17 & 8888 & 13 & 9436 & 10 \\
Southern Region & Otago/Southland & 4432 & 21 & 4309 & 16 & 4480 & 14 \\
\hline \multicolumn{2}{l}{ Total children with reports of concern } & 90,893 & 25 & 83,871 & 20 & 81,840 & 18 \\
\hline
\end{tabular}

* Data from Ministry of Social Development Key Statistics.

Differences in relation to placement type and ethnicity of children in the care of the chief executive of the statutory child protection agency also hint at inequalities. The biggest growth in placement type is for family and whānau (extended family) placements-up from 1698 in 2013, to 2515 in 2017. Does this reflect a growing preference for kin-based care, or a lack of non-kin foster carer availability? There is also a growing disproportionate percentage of Māori children in care, up from $55 \%$ of children in care in 2013, to $62 \%$ in 2017 (despite being 25\% of the child population) (Ministry of Social Development 2018). The proportion of Pākeha (European ancestry) children in care over the same period has dropped, from $33 \%$ in 2013 , to $27 \%$ in 2017, while Pacific (8-7\%), Asian children (1.4-1.6\%) and children with multiple ethnicities (2-1.4\%) all remain steady (Ministry of Social Development 2018). A further question is whether the increased percentage of children in contact with child protection services who are Māori is related to increasing exposure to poverty, an increase in implicit bias in the systems that respond (including surveillance bias), or the lack of culturally appropriate prevention services. It may also be heightened by the practice of prioritising ethnicity data so that the growing multiple ethnicity child population are categorised as Māori only, depressing counts of children from other ethnic groups (Cram et al. 2015; Cormack and Robson 2010). All of these questions would benefit from exploring from an inequalities perspective, as this assists with understanding the systemic factors contributing to system contact.

\section{Understanding Patterns of System Contact: The Intersectionality of Deprivation, Ethnicity and Location}

Bywaters et al. (2016d) argues that: “The differences in rates between Local Authorities (council areas) and between neighbourhoods are not a postcode lottery nor are they simply the result of random differences in LA policies and practice; they are markers of social inequalities" (p. 7). Determining if the differences in rates of intervention have a relationship with deprivation or other types of inequalities, in combination with site-related factors such as supply and demand of services or differences in decision-making, are key areas requiring investigation in Aotearoa New Zealand. While we have as yet limited evidence of the nuances of this relationship explicitly framed within an inequalities perspective, some research provides useful windows into possible links. For example, the recent Expert Panel report into Child Youth and Family (the statutory child protection service) shows that $88 \%$ of those seen by child protection services by age 5 had at least one parent in receipt of a welfare benefit, compared to $30 \%$ of those who had no contact with child protection services, while $46 \%$ of those with contact with child protection services lived in a high deprivation area, compared to $26 \%$ of those with no child protection notifications (Expert Panel 2015). In terms of the possible influence of site office, predictive modelling suggests that site office may have a substantial influence on decision outcomes. 
A study by Wilson et al. (2015) reported that site office was the 4th most predictive variable from thirteen variables "when the effect of other variables was controlled" (p. 510). This suggests that over and above the other variables (many of which could be considered proxies for poverty-the three most predictive were previous contact with child protection services, length of time on a benefit, and having a parent with child protection system contact), site office remains a strong predictor. This suggests that deprivation and other macro inequalities interact with site factors to influence outcomes.

Other work also suggests more nuanced relationships between poverty, contact with the child protection system, and poor adult outcomes (Ball et al. 2016; Crichton et al. 2016; Templeton et al. 2016). Crichton et al. (2015) found that three factors had particularly strong correlations with these poor social outcomes: referral to youth justice, lack of NCEA level 2 (National Certificate of Educational Achievement-a key high school educational qualification), and receipt of a benefit as an adult. The three risk factors were: "the proportion of time the child had been supported by benefits since birth; having a parent/caregiver with a corrections history (including both community and custodial sentences); being notified to Child Youth and Family (child protection services) (pp. 32-33, brackets mine)". These all suggest a strong relationship between high deprivation and contact with child protection services (O'Brien 2016; Keddell 2017). These studies give some insight into the connections between deprivation and contact with the child protection system, but do not explicitly frame these as markers of inequalities and therefore a justice issue.

A persistent inequality, as mentioned above, in the Aotearoa New Zealand child protection domain is that related to ethnicity. In the last five years, Aotearoa NZ has seen continued Māori overrepresentation in the child protection and foster care population. Understanding the rates of Māori child protection system contact across deprivation levels compared to other ethnic groups is important, as this would help understand the relationship between the two axes of inequality (meeting the 'intersectional' criteria of inequalities research as described above). One study has examined this intersection. Cram et al. (2015) found that amongst Māori who had spent at least four out of the last five years on a welfare benefit (as a proxy for poverty), the rate for this group of substantiated child abuse findings was 156.38/1000 births, and the infant mortality rate was 6.17/1000. For Māori who had spent no time in the last five years in receipt of benefit, the rate of substantiation was 8.73/1000 births, and infant mortality 1.7/1000. For non-Māori, non-Pacific the same rates were 119.06 (3.68) and 3.52 (0.91). This shows marked differences that relate not only to ethnicity but to the combination of ethnicity and deprivation.

International research has explored the relationships between ethnicity and different levels of deprivation. Depending on context, some conclude that while children from indigenous and ethnic minorities are overrepresented, when deprivation is taken into account differences between ethnic groups can disappear or even reverse. For example, Bywaters et al. (2016b) found that of children in the poorest decile in the UK, Black children had a lower rate of contact than White children, and that "mixed heritage" children had a higher rate than both. Wulczyn et al. (2013) found that there was a 'placement gap' between African-American and white American children that was reduced by introducing poverty as a variable, while Drake et al. (2009) found, similarly to Bywaters et al. in the English context, that poor White children had a higher rate of contact with child protection system than African-American poor children (Drake et al. 2009). Others have also concluded that ethnic disparities generally reduce as deprivation increases (Kim et al. 2011).

Here in Aotearoa New Zealand, due to significant and increasing overrepresentation, it is important that research attempts to unpick the interrelationships between poverty, ethnicity and bias that are likely contributors to the disproportionate representation of Māori children. Since the 1980s, many have noted that institutional bias, both explicit and implicit, has resulted in more state intervention for Māori children than for others, and is part of the long history of cultural oppression of Māori (Ministerial Committee 1988; Cram 2012; Reid et al. 2016). It is likely that for Māori particularly, exposure to poverty is not the only factor that may be contributing to increased risk. Other factors identified in the literature include everyday exposure to racism, cultural oppression, negative 
media representation, and the alienation of material resources due to the process of colonisation (Blank et al. 2013; Cram 2012; Hackell 2016). The relationship between neighborhood ethnic density and deprivation may also affect exposure to the stressors associated with increased risk of need for child protection services, as high ethnic density may operate as a protective factor, but can be offset by exposure to high deprivation (Bécares et al. 2013; Cram et al. 2015). The process of being assigned ethnicity by others may also influence the ability of some Māori to access appropriate support services, as has been found in health service access (Reid et al. 2016).

In Aotearoa New Zealand, one study has examined in some depth the intersection between risk and bias, attempting to discover to what extent the overrepresentation of Māori children is related to heightened exposure to risk factors, or bias within the child protection system (Cram et al. 2015). In this nuanced study, a range of rates of poor outcomes outside the child protection system were examined for Māori children compared to the rates inside the system, as a method (Drake et al. 2009) to ascertain if the disproportionate rates indicated risk over bias. The range of outcomes outside of the child protection system examined were benefit use, mortality and other poor birth outcomes, accidents and hospitalisation rates. They found similarly poor rates for outcomes outside the child protection system for Māori. They draw tentative conclusions from this, stating that " ... focusing on 'poverty and its correlates' when attempting to address the overrepresentation of indigenous children in administratively recorded maltreatment may effect more change than focusing on the attitudes of those who come in contact with children and their families" (p. 8). However, they point out that the similarities between risk measures they used and child protection outcomes do not necessarily preclude the additional effect of bias within the child protection system (p. 9). They also conclude that the traditional risk/bias split may not adequately account for contextual factors such as the history of colonisation, the provision of culturally appropriate (or not) services and the protective factors embedded in Māori culture (Cram et al. 2015; Drake et al. 2009, 2011). They argue for a more complex understanding of indigenous disproportionality.

Other studies of indigenous children also draw complex conclusions. For example, a study based on national data in Canada found that the overrepresentation of Aboriginal children in the Canadian child welfare system was not adequately explained by child maltreatment type, child functioning, or levels of harm. Instead, overrepresentation at all decision points (investigation, substantiation and removal) were associated with poverty, poor housing and substance abuse, pointing to structural disadvantage as the primary factor, rather than either case factors or bias (Fallon et al. 2013). Drake et al. (2011) found that the disparity in child protection system data matched the data on other poorer outcomes for Black children, particularly neonatal deaths, concluding that although decision-making bias may play a role, a more effective way to reduce racial disproportionality in the CPS system would be to address known risk factors that affect African-American families in the US, rather than address racial bias in the CPS system. On the other hand, some studies have found that race does increase perceptions of risk that result in differences in service outcomes (Ards et al. 2012; Williams and Soydan 2005). Rates of contact for Māori may also be related more directly to bias. For example, the overrepresentation of tamariki Māori (children) increases at each decision point within the child protection system, with $40 \%$ of children notified being Māori (who are 25\% of the child population), but this increases to $60 \%$ by the time decisions to remove children into foster care are made (Expert Panel 2015; Statistics New Zealand 2016).

A further possible piece of the puzzle when considering the relationships between deprivation and ethnicity is the influence of culturally appropriate preventive/support services. For example, Fluke et al. (2010) investigated the influence of organisational factors on the rates of decisions to remove Aboriginal children in the Canadian Incidence study. While Aboriginal status and structural factors such as poverty and housing were influential, they found that the only organisational factor that affected this outcome was the relative proportion of Aboriginal children notified to particular site offices. They conclude that the provision of culturally appropriate services outside the formal child protection system affects rates of Aboriginal children entering the child protection system, as 
without those services, when faced with high numbers of Aboriginal referrals, the child protection system may have little choice but to intervene. These are all important issues affecting the patterns of inequalities for Māori in the child protection system. The issues for children from ethnic groups other than Māori and Pākeha may also have aspects that could be examined from an inequalities perspective. Disproportionate rates of notification for Pacific children, for example, nearly disappear by the removal decision point, despite high levels of community deprivation (Ministry of Social Development 2018).

\section{Building a Research Agenda}

Current research and policy directions in Aotearoa New Zealand have drawn increasing attention to persistent risk factors across the population for poor outcomes in education and criminal justice, and link this to a 'social investment' policy agenda (Ball et al. 2016; Crichton et al. 2015). This has a strong focus on outcomes, explained by individual risk factors and the cumulative nature of those risk factors for individuals across the lifespan. An inequalities perspective builds on this base, using a different lens with which to analyse data, motivated not only by future economic considerations but by a concern with human rights and social justice. In other words, the argument for greater equality in child protection is not just to avoid costs to the state from poor outcomes, but also because it is a moral imperative. The state's obligation to protect and promote the development of children under the Convention of the Rights of the Child is incompatible with accepting very unequal childhood experiences, including experiences of abuse and neglect, receipt of services, or being separated from your birth parents.

An inequalities research agenda can be separated into three categories of chances, experience and outcomes. Chances focus on who is subject to interventions or gets access to services and how this relates to inequalities; experience focusses on the experiences of different groups once they are in the system; and outcomes aims to establish how inequalities affect the outcomes of system contact (Bywaters 2013). Research questions relating to the chances of contact include:

1. What are the relationships between social inequalities and various decision points in the child protection system?

2. Does a social gradient exist and how steep is it?

3. What are the rates of Māori, Pākeha, Pacific and Asian children at each decision point, by level of deprivation?

4. How do the same levels of deprivation in different locations compare with each other in relation to child protection system contact, that is, is there an 'inverse intervention law' operating?

Of particular interest in relation to ethnicity, incorporating the risk-bias literature, is the question of whether or not there are increasing levels of deprivation as severity of child protection system contact points increases and to what extent does this explain the overrepresentation of Māori children? If so, does this mean that Māori children are presenting at the 'front-door' of the child protection system with more serious and complex problems than other children relating to their over-exposure to deprivation; or is this increasing overrepresentation the result of bias? This has important system design implications. If risk is increased, then more emphasis is needed on addressing poverty and access to services-if the issue is more strongly affected by bias, then patterns of surveillance and direct bias require correcting within child protection systems.

Qualitative approaches are also needed to understand how chances of contact may be shaped by perceptions and responses of various social actors: policy makers and politicians; managers and service leaders; front line staff; parents; children; and the wider public. Research must cover their perspectives and experiences. In terms of experiences, the different pathways of children and their families once in the system require investigation, with a view to identifying differential pathways that may be related to deprivation, ethnicity, or some other type of inequality such as disability or location. This type of research would examine the relative roles of risk, bias, and demand and supply to describe and explain differences in experiences. Questions could include to what extent expenditure 
for different areas, groups and ages of children reflects levels of need and whether the type of service provision is equally appropriate and accessible to different groups. Again, while some of these research questions should be quantified, qualitative research into the experiences of practitioners in the system and of children and families in the child protection system are also required. Finally, studies of the outcomes of children who have been in the child protection system and their families is needed, and the relationships of various groups to inequalities examined. Is it, for example, that children removed from more middle-class families do better? Or that different types of foster care (which is differentially resourced) affect children's outcomes?

In conclusion, the evidence base in relation to inequalities in the Aotearoa New Zealand context is slowly growing. Understanding the complex interplay between markers of inequality and contact chances, experiences and outcomes of the child protection system provides a substantial lens for framing future research, one that may assist with informing policies that can address 'upstream' determinants in addition to the downstream effects of child protection system contact.

Author Contributions: E.K. conceptualized, wrote and edited the article, G.D. contributed to concepts, edited text and provided statistical presentation editing.

Funding: This research received no external funding.

Acknowledgments: The authors would like to acknowledge Paul Bywaters and Kate Morris for extensive and helpful feedback on earlier drafts of this article.

Conflicts of Interest: The authors declare no conflicts of interest.

\section{References}

Ards, Sheila, Samuel Myers, Jr., Chanjin Chung, Malkis Allan, and Brian Hagerty. 2012. Racialized perceptions and child neglect. Children and Youth Services Review 34: 1480-91. [CrossRef] [PubMed]

Ball, Chris, Sarah Tumen, Sarah Crichton, and Robert Templeton. 2016. Characteristics of Children at Greater Risk of Poor Outcomes as Adults. Edited by N. Z. Treasury. Wellington: New Zealand Government.

Bécares, Laia, Donna Cormack, and Ricci Harris. 2013. Ethnic density and area deprivation: Neighbourhood effects on Māori health and racial discrimination in Aotearoa/New Zealand. Social Science E Medicine 88: 76-82.

Bilson, Andy, and Katie Martin. 2016. Referrals and child protection in England: One in five children referred to children's services and one in nineteen investigated before the age of five. British Journal of Social Work 47: 793-811. [CrossRef]

Blank, Anton, Fiona Cram, Tim Dare, Irene de Haan, Barry Smith, and Rhema Vaithianathan. 2013. Ethical Issues for Maori in Predictive Risk Modelling to Identify New-Born Children Who Are at High Risk of Future Maltreatment. Wellington: Ministry of Social Development.

Bradt, Lievre, Griet Roets, Rudi Roose, Yves Rosseel, and Maria Bouverne-De Bie. 2015. Poverty and decision making in child welfare and protection: Deepening the bias-need debate. British Journal of Social Work 45: 2161-75. [CrossRef]

Boyd, Reiko. 2014. African American disproportionality and disparity in child welfare: Toward a comprehensive conceptual framework. Children and Youth Services Review 37: 15-27.

Bywaters, Paul, Eileen McLeod, and Lindsay Napier. 2009. Social Work and Global Health Inequalities: Practice and Policy Development. Bristol: Policy Press.

Bywaters, Paul. 2013. Inequalities in child welfare: Towards a new policy, research and action agenda. British Journal of Social Work 45: 6-23. [CrossRef]

Bywaters, Paul, Geraldine Brady, Tim Sparks, Elizabeth Bos, Lisa Bunting, Brigid Daniel, Brid Featherstone, Kate Morris, and Jonathan Scourfield. 2015. Exploring inequities in child welfare and child protection services: Explaining the 'inverse intervention law'. Children and Youth Services Review 57: 98-105. [CrossRef]

Bywaters, Paul, Geraldine Brady, Tim Sparks, and Elizabeth Bos. 2016a. Child welfare inequalities: New evidence, further questions. Child E Family Social Work 21: 369-80.

Bywaters, Paul, Geraldine Brady, Tim Sparks, and Elizabeth Bos. 2016b. Inequalities in child welfare intervention rates: The intersection of deprivation and identity. Child \& Family Social Work 21: 452-63. 
Bywaters, Paul, Lisa Bunting, Gavin Davidson, James Hanratty, Will Mason, Claire McCartan, and Nicole Steils. 2016c. The Relationship between Poverty, Child Abuse and Neglect: An Evidence Review. Coventry: Joseph Rountree Foundation.

Bywaters, Paul, Brid Featherstone, Will Mason, Kate Morris, and Emily Keddell. 2016d. Interventions and inequalities: Do child welfare interventions reveal, reinforce or redress inequalities? Paper presented at the Social, the Biological and the Material Child, CSCY 6th International Conference, Sheffield, UK, July 7.

Bywaters, Paul, Geraldine Brady, Lisa Bunting, Brigid Daniel, Brid Featherstone, Chantel Jones, Kate Morris, Jonathan Scourfield, Tim Sparks, and Calum Webb. 2018. Inequalities in English child protection practice under austerity: A universal challenge? Child \& Family Social Work 23: 53-61.

Collins, Simon. 2014. More living in cars as rents go through roof. New Zealand Herald, October 4.

Cancian, Maria, Kirsten Shook Slack, and Mi-Joun Yang. 2013. The effect of additional child support income on the risk of child maltreatment. Social Service Review 87: 417-37. [CrossRef]

Conrad-Hiebner, Aislin, and Kathrine Paschall. 2017. Determining risk for child physical harm through the classification of economic insecurity. Children and Youth Services Review 78: 161-69. [CrossRef]

Cormack, Donna, and Carey Robson. 2010. Classification and Output of Multiple Ethnicities: Issues for Monitoring Māori Health. Wellington: Te Rōpū Rangahau Hauora a Eru Pōmare.

Coulton, Claudia J., David Crampton, Molly Irwin, James Spilsbury, and Jill E. Korbin. 2007. How neighborhoods influence child maltreatment: A review of the literature and alternative pathways. Child Abuse $\mathcal{E}$ Neglect 31: 1117-42.

Cram, Fiona. 2012. Safety of Subsequent Children: Māori Children and Whānau. Wellington: NZ Government.

Cram, Fiona, Pauline Gulliver, Rissa Ota, and Moira Wilson. 2015. Understanding overrepresentation of Indigenous children in child welfare data: An application of the Drake risk and bias models. Child Maltreat 20: 170-82. [CrossRef] [PubMed]

Crichton, Sarah, Rob Templeton, and Sarah Tumen. 2015. Using Integrated Administrative Data to Understand Children at Risk of Poor Outcomes as Young Adults. Analytical Paper 15/01. Wellington: New Zealand Treasury.

Crichton, Sarah, Robert Templeton, Sarah Tumen, Rissa Ota, Debra Small, Moira Wilson, and David Rea. 2016. New Findings on Outcomes for Children and Young People Who Have Contact with Child, Youth and Family. Edited by Ministry of Social Development NG. Wellington: Ministry of Social Development NG.

Dale, Clare, Mike O’Brien, and Susan St John. 2014. Our Children, Our Choice: Priorities for Policy. Auckland: Child Poverty Action Group.

Detlaff, Alan. 2014. The Evolving Understanding of Disproportionality and Disparities in Child Welfare. In Handbook of Child Maltreatment. Edited by Jill E. Korbin and Richard Krugman. Dordrecht: Springer, pp. 149-60.

Detlaff, Alan, Stephanie Rivaux, Donald Baumann, John Fluke, Joan Rycraft, and Joyce James. 2011. Disentangling substantiation: The influence of race, income, and risk on the substantiation decision in child welfare. Children and Youth Services Review 33: 1630-37. [CrossRef]

Dew, Kevin, and Anna Matheson. 2009. Understanding Health Inequalities in Aotearoa New Zealand. Dunedin: Otago University Press.

Dew, Kevin, Anne Scott, and Allison Kirkman. 2016. Social, Political and Cultural Determinants of Health. Basel: Springer.

Drake, Brett, Sang Moo Lee, and Melissa Jonson-Reid. 2009. Race and child maltreatment reporting: Are Blacks overrepresented? Children and Youth Services Review 31: 309-16. [CrossRef] [PubMed]

Drake, Brett, Jennifer Jolley, Paul Lanier, John Fluke, Richard Barth, and Melissa Jonson-Reid. 2011. Racial bias in child protection? A comparison of competing explanations using national data. Pediatrics 127: 471-78. [CrossRef] [PubMed]

Eckenrode, John, Elliote G. Smith, Margaret Elanor McCarthy, and Michael Dineen. 2014. Income Inequality and Child Maltreatment in the United States. Pediatrics 133: 454-61. [CrossRef] [PubMed]

Expert Panel. 2015. Expert Panel Final Report: Investing in New Zealand's Children and their Families. Edited by Development MoS. Wellington: Ministry of Social Development.

Fallon, Barbars, Martin Chabot, John Fluke, Cindy Blackstock, Bruce MacLaurin, and Lil Tonmyr. 2013. Placement decisions and disparities among Aboriginal children: Further analysis of the Canadian incidence study of reported child abuse and neglect part A: Comparisons of the 1998 and 2003 surveys. Child Abuse E Neglect 37: $47-60$. 
Fluke, John, Martin Chabot, Barbara Fallon, Bruce MacLaurin, and Cindy Blackstock. 2010. Placement decisions and disparities among aboriginal groups: An application of the decision making ecology through multi-level analysis. Child Abuse \& Neglect 34: 57-69.

Font, Sarah, Lawrence Berger, and Kirsten Shlook Slack. 2012. Examining racial disproportionality in child protective services case decisions. Children and Youth Services Review 34: 2188-200. [CrossRef] [PubMed]

Gilbert, Neil. 2012. A comparative study of child welfare systems: Abstract orientations and concrete results. Children and Youth Services Review 34: 532-36.

Gilbert, Neil, Nigel Parton, and Marit Skivenes. 2011. Child Protection Systems: International Trends and Orientations. Oxford: Oxford University Press.

Hackell, Melissa. 2016. Managing anxiety: Neoliberal modes of citizen subjectivity, fantasy and child abuse in New Zealand. Citizenship Studies 20: 867-82.

Johnson-Reid, Melissa, Brett Drake, and Patricia Kohl. 2009. Is the overrepresentation of the poor in child welfare caseloads due to bias or need? Children and Youth Services Review 31: 422-27. [CrossRef] [PubMed]

Keddell, Emily. 2017. The Child Youth and Family Review: A Commentary on Prevention. Auckland: The Policy Observatory.

Kim, Hyunil, David Chenot, and Juye Ji. 2011. Racial/ethnic disparity in child welfare systems: A longitudinal study utilizing the disparity index (di). Children and Youth Services Review 33: 1234-44. [CrossRef]

Kim, Hyunil, Brett Drake, and Melissa Jonson-Reid. 2018. An examination of class-based visibility bias in national child maltreatment reporting. Children and Youth Services Review 85: 165-73. [CrossRef]

Klein, Sacha, and Darcy Merritt. 2014. Neighborhood racial \& ethnic diversity as a predictor of child welfare system involvement. Children and Youth Services Review 41: 95-105.

Maguire-Jack, Katherine, and Sarah Font. 2017. Intersections of individual and neighborhood disadvantage: Implications for child maltreatment. Children and Youth Services Review 72: 44-51. [CrossRef]

McLaughlin, Michael, and Melissa Jonson-Reid. 2017. The relationship between child welfare financing, screening, and substantiation. Children and Youth Services Review 82: 407-12. [CrossRef]

Melton, Gary. 2005. Mandated reporting: A policy without reason. Child Abuse and Neglect 29: 9-18. [CrossRef] [PubMed]

Ministerial Committee. 1988. PUAO-TE-ATA-TU (Day Break): The Report of the Ministerial Advisory Committee on a Maori Perspective for the Department of Social Welfare. Edited by Welfare DoS. Wellington: Ministerial Committee.

Ministry of Social Development. 2016. Personal communication, population denominators for each site office.

Ministry of Social Development. 2018. Key Statistics and Information for Media. Available online: http:/ / www. msd.govt.nz/about-msd-and-our-work/publications-resources/statistics/cyf/ (accessed on 18 March 2018).

Molnar, Beth, Robert Goerge, Paola Gilsanz, Andrea Hill, SV Subramanian, John Holton, Dustin Duncan, Elizabeth Beatriz, and William Beardslee. 2016. Neighborhood-level social processes and substantiated cases of child maltreatment. Child Abuse E Neglect 51: 41-53.

Morris, Kate, Will Mason, Paul Bywaters, Brid Featherstone, Brigid Daniel, Geraldine Brady, Lisa Buntin, Jade Hooper, Nughmana Mirza, Jonathan Scourfield, and et al. 2018. Social work, poverty, and child welfare interventions. Child \& Family Social Work 2018: 1-9. [CrossRef]

Nadan, Yochay, James Spilsbury, and Jill Korbin. 2015. Culture and context in understanding child maltreatment: Contributions of intersectionality and neighborhood-based research. Child Abuse E Neglect 41: 40-48.

National Audit Office. 2016. Children in Need of Help or Protection. London: National Audit Office.

O'Brien, Mike. 2016. The triplets: Investment in outcomes for the vulnerable-Reshaping social services for (some) New Zealand children. Aotearoa New Zealand Social Work 28: 9-21.

Parton, Nigel. 2010a. 'From dangerousness to risk': The growing importance of screening and surveillance systems for safeguarding and promoting the well-being of children in England. Health, Risk E Society 12: 51-64.

Parton, Nigel. 2010b. International comparison of child protection systems. Paper presented at SFI Conference 2010, Copenhagen, Denmark, September 7-9. Unpublished.

Peacock, Marian, Paul Bissell, and Jenny Owen. 2014. Dependency denied: Health inequalities in the neo-liberal era. Social Science $\mathcal{E}$ Medicine 118: 173-80.

Pelton, Leroy. 2015. The continuing role of material factors in child maltreatment and placement. Child Abuse $\mathcal{E}$ Neglect 41: 30-39.

Perry, Bruce. 2015. Household Incomes in New Zealand: Trends in Indicators of Inequality and Hardship 1982 to 2014. Wellington: Ministry of Social Development. 
Putnam-Hornstein, Emily, Barbara Needell, Bryn King, and Michelle Johnson-Motoyama. 2013. Racial and ethnic disparities: A population-based examination of risk factors for involvement with child protective services. Child Abuse \& Neglect 37: 33-46.

Raissian, Kerri, and Lindsay Bullinger. 2016. Money matters: Does the minimum wage affect child maltreatment rates? Children and Youth Services Review, 72. [CrossRef]

Reid, Jennifer, Donna Cormack, and Marie Crowe. 2016. The significance of socially-assigned ethnicity for self-identified Māori accessing and engaging with primary healthcare in New Zealand. Health 20: 143-60. [CrossRef] [PubMed]

Roberts, Helen. 2012. What Works in Reducing Inequalities in Child Health? Bristol: Policy Press.

Rouland, Benedicte, and Rhema Vaithianathan. 2018. Cumulative Prevalence of Maltreatment among New Zealand Children, 1998-2015. American Journal of Public Health 108: 511-13. [CrossRef] [PubMed]

Shuey, Elizabeth, and Tama Leventhal. 2017. Pathways of risk and resilience between neighborhood socioeconomic conditions and parenting. Children and Youth Services Review 72: 52-59. [CrossRef]

Simpson, Jean, Mavis Duncanson, G. Oben, A. Wicken, and N. Pierson. 2015. Child Poverty Monitor 2015 Technical Report. Dunedin: NZ Child \& Youth Epidemiology Service, University of Otago.

Simpson, Jean, Mavis Duncanson, G. Oben, A. Wicken, and N. Pierson. 2016. Child Poverty Monitor: Technical Report 2016 (National Report). Dunedin: Dunedin New Zealand Child and Youth Epidemiology Service.

Slack, Kirsten Shlook, Lawrence Berger, and Jennifer Noyes. 2017. Introduction to the special issue on the economic causes and consequences of child maltreatment. Children and Youth Services Review 72: 1-4. [CrossRef]

Spratt, Trevor. 2008. Possible Futures for Social Work with Children and Families in Australia, the United Kingdom and the United States. Child Care in Practice 14: 413-27. [CrossRef]

Statistics New Zealand. 2016. Estimates and Projections. Wellington: NZ Government.

Stokes, Jaqueline, and Glen Schmidt. 2011. Race, poverty and child protection decision making. British Journal of Social Work 41: 1105-21. [CrossRef]

Templeton, Robert, Sarah Crichton, Sarah Tumen, and Rissa Ota. 2016. Research Using Adminstrative Data to Support the Work of the Expert Panel on Modernising Child Youth and Family. Edited by N. Z. Treasury. Wellington: NZ Government.

Wells, Susan, Lani Merritt, and Harold Briggs. 2009. Bias, racism and evidence-based practice: The case for more focused development of the child welfare evidence base. Children and Youth Services Review 31: 1160-71. [CrossRef]

Widom, Cathy, Sally Czaja, and Kimberley DuMont. 2015. Intergenerational transmission of child abuse and neglect: Real or detection bias? Science 347: 1480-85. [CrossRef] [PubMed]

Williams, Charlotte, and Halyuk Soydan. 2005. When and how does ethnicity matter? A cross-national study of social work responses to ethnicity in child protection cases. British Journal of Social Work 35: 901-20. [CrossRef]

Wilson, Moira, Sarah Tumen, Rissa Ota, and Anthony Simmers. 2015. Predictive Modeling: Potential Application in Prevention Services. American Journal of Preventive Medicine 48: 509-19. [CrossRef] [PubMed]

Wilkinson, Richard, and Kate Pickett. 2009. The Spirit Level: Why More Equal Societies Almost Always Do Better. London: Allen Lane.

Woodward, Alistair, and Tony Blakely. 2016. The Healthy Country? A History of Life and Death in New Zealand. Auckland: Auckland University Press.

Wulczyn, Fred, Robert Gibbons, Lonnie Snowden, and Bridget Lery. 2013. Poverty, social disadvantage, and the black/white placement gap. Children and Youth Services Review 35: 65-74. [CrossRef]

(C) 2018 by the authors. Licensee MDPI, Basel, Switzerland. This article is an open access article distributed under the terms and conditions of the Creative Commons Attribution (CC BY) license (http:// creativecommons.org/licenses/by/4.0/). 